\title{
LA REGULACIÓN DE LA MATERNIDAD SUBROGADA EN LOS ESTADOS DE TABASCO Y SINALOA. COMPARATIVA CON LA PROHIBICIÓN DE MATERNIDAD POR SUSTITUCIÓN DEL DERECHO ESPAÑOL
}

\section{Lorenzo Álvarez de TOLEdo QuinTANA'}

RESUMEN: El presente trabajo tiene por objeto analizar de forma sucinta y sin ningún propósito agotador, el estado de la cuestión de la maternidad subrogada en dos modelos jurídicos de signos opuestos: el modelo español, en el que rige la prohibición de la maternidad subrogada; y los de dos Estados mexicanos, Tabasco y Sinaloa, donde se regula el proceso procreativo con determinadas garantías para la parte más débil de la relación jurídica, la madre gestante.

Es mi propósito defender la necesidad de una urgente regulación en España que dé una respuesta completa, actualizada y respetuosa con la dignidad y derechos fundamental de todas las partes: primordialmente, del niño por nacer, que, a diferencia de lo que ocurre en la adopción (se busca una familia para el niño) supone la búsqueda de un hijo para una familia.

El examen del derecho comparado ofrece una herramienta insustituible en la búsqueda del Derecho justo y el examen -necesariamente breve- de los modelos jurídicos de tabasco y de Sinaloa, representa un avance hacia el debate que queremos y necesitamos en España.

PALABRAS CLAVE: maternidad subrogada, dignidad interés superior del menor, derechos fundamentales, padres intencionales, contrato de maternidad subrogada.

ABSTRACT: The purpose of the present work is to analyze succinctly and without any exhausting purpose, the state of the question of surrogate motherhood in two legal models of opposing signs: the Spanish model, governed by the prohibition of surrogacy; and those of two Mexican states, Tabasco and Sinaloa, where the

1 Doctor en Derecho por la Universidad de León, España, con tesis GUM LAUDE sobre Derecho Internacional Privado; profesor de Derecho Civil en la Universidad de León y Magistrado en la Audiencia Provincial de León. 
procreative process is regulated with certain guarantees for the weakest part of the legal relationship: the pregnant mother.

It is my purpose to defend the need for an urgent regulation in Spain that gives a complete, up-to-date and respectful response to the fundamental dignity and rights of all parties: primarily, the unborn child, who, unlike what happens in adoption (looking for a family for the child) is the search for a child for a family.

The examination of comparative law offers an irreplaceable tool in the search for fair law and the -necessarily brief- review of the legal models of Tabasco and Sinaloa involves an advance towards the debate that we want and need in Spain.

Keywords: Surrogate motherhood, Human dignity, Best interest of the child, Fundamental rights, Intended parents, surrogate parents, Surrogacy arrangement.

SuMARIO: I. Introducción; II. La Situación de la maternidad subrogada en España; III. El discurso de la dignidad; IV. El comercio con el cuerpo de la mujer y la vida del niño por nacer; $\mathrm{V}$. Breve exposición del régimen de la maternidad subrogada en dos estados mexicanos; VI. Epílogo.

\section{INTRODUCCIÓN}

71 camino que algunos Estados del hemisferio sur han seguido de incorporar a sus ordenamientos jurídicos una regulación de la procreación por sustitución requería, no solamente un cauce de realización técnica, consistente en el auxilio de la ciencia biomédica, sino también otro jurídico, a través de la regulación que contenga en un doble sentido, de tener-en y de con-tener las pautas que se han de observar para la que en ningún momento del proceso tecnológico ni del establecimiento de la filiación, se produzca una rebaja de la dignidad de las partes intervinientes: del niño que cuya filiación se trata de establecer, de la madre biológica que ha renunciado a una porción nada despreciable de su intimidad y de su salud para dar a luz a aquel; y de los aspirantes a la paternidad, cuyo derecho a formar una familia completa debe quedar definido y co- 
rectamente ubicado en el lugar apropiado de nuestras constituciones y convenios internacionales.

Los avances de la técnica están a punto de colocar en las manos del homo sapiens las llaves de la evolución misma de la especie, lo que tenemos que mirar con alguna ambigüedad, como horizonte esperanzador y también como una frontera peligrosa que convendría cruzar con paso cauteloso, buena montura y mejor armadura.

Lo cierto es que la maternidad subrogada se nos aparece hoy como el único camino que algunas parejas pueden surcar en la búsqueda de la intimidad familiar y de la felicidad personal. Estamos obligados, pues, a preguntarnos si el Derecho no puede brindarnos los posibilidad de garantizar los derechos fundamentales de la madre alumbrante ${ }^{2}$ que va a renunciar a la maternidad, y hacerlos compatibles con los demás intereses en presencia.

\section{LA Situación DE LA MATERNidAd SUBROgada SN ESPAÑa}

En España, la práctica de la gestación por sustitución se encuentra terminantemente prohibida por el art. 10 de la Ley de Técnicas de Reproducción Asistida de 2006, a cuyo tenor:

1. Será nulo de pleno derecho el contrato por el que se convenga la gestación, con o sin precio, a cargo de una mujer que renuncia a la filiación materna a favor del contratante o de un tercero.

2 Lo que evidentemente supone el rechazo algunos los muy liberales y ciertamente repugnantes pactos que podemos leer en las cláusulas de algunos los contratos de maternidad subrogada al uso, en los que se conviene una retribución muy distinta para la mujer alumbradora, en función de que se produzca o no el parto; que el hijo alumbrado sea niño, o niña; que sea uno sólo o más... que nazca sin malformaciones o que aforen en su cuerpo los rasgos de una raza determinada, indicativos de una procedencia que no se advertía físicamente en la madre... pactos que evidentemente son la resultancia de una concepción mercantilista, que rechazamos por ser frontalmente contraria a la dignidad y derechos consagrados en los arts. 10 y 14 de la Constitución española y concordantes de los convenios sobre derechos humanos ratificados por España. 
2. La filiación de los hijos nacidos por gestación de sustitución será determinada por el parto.

3. Queda a salvo la posible acción de reclamación de la paternidad respecto del padre biológico, conforme a las reglas generales.

Se sigue de lo anterior que, en el marco del derecho español interno, no es posible reconocer la condición de madre a otra persona que a la mujer alumbradora, que ha engendrado y ha tenido al niño en un parto natural. Ello va tener insospechadas y muy dañosas consecuencias, como veremos más adelante

Hace años, una corriente humanista de pensamiento se apoderó de la Dirección General de los Registros y del Notariado, institución que rige la inscripción en el Registro Civil español de los actos relativos al estado civil y por lo tanto, de los nacimientos y de la filiación de los nacidos inscritos, y empezó a utilizar inteligentemente los mecanismos de Derecho Internacional Privado, en particular al reconocimiento en España de las decisiones extranjeras, para hacer posible que los padres que viajaban a algún estado permisivo con la maternidad subrogada, pudieran obtener del Registro Civil español el reconocimiento de su paternidad.

Aunque la Dirección General de los Registros y del Notariado era extremadamente rigurosa con los requisitos que se exigían a los padres intencionales que regresaban del extranjero con el niño bajo un brazo y con la documentación extranjera en la otra $-\mathrm{y}$ en modo alguno puede censurársele por eso- admitían que, a pesar de la prohibición establecida en nuestra ley, en el art. 10 de la Ley de Técnicas de Reproducción Asistida no representaba un obstáculo insuperable para hacer realidad los sueños de las parejas impedidas de procrear. $^{3}$

Sin embargo, el Tribunal Supremo español ha puesto fin a esa situación al declarar, en su Sentencia de 6 de febrero de 2014, que

3 Algunas de ellas, homosexuales, pues en España es admisible el matrimonio entre personas del mismo sexo, desde 2005. 
el art. 10 de la Ley de 2006 constituye orden publico frente al cual no puede oponerse ningún pacto entre padres comitentes y madre gestante, aunque haya sido concluido en el extranjero y aunque haya generado un vinculo de filiación válido, en otro Estado.

Ahora, los juristas nos preguntamos: ¿En qué situación quedan los niños nacidos en el extranjero, de padre españoles, resultado de una operativa de maternidad por sustitución? Porque, según la ley española, la madre legal es la que no quiere serlo. Y quienes quieren ser padres, no tienen ninguna posibilidad, salvo el padre que haya aportado su material genético, en los términos del art. 10.3 de la Ley. Así que el niño engendrado con estas técnicas en, por ejemplo, california, EE.UU - porque en México los padres españoles tienen vedado el acceso a la procreación por sustitución- tiene unos padres legales determinados (los padres comitentes o intencionales) en California; pero, al pasar la frontera y quedar en suelo español, la madre del niño es la madre californiana que ha renunciado expresamente a la maternidad. Y si ésta se encuentra casada, con arreglo al derecho español, el padre del nacido es el esposo de la mujer gestante que ha renunciado a la maternidad. ${ }^{4}$

Como consecuencia de tal esquizofrénica formación de su identidad, el niño no puede decir quiénes son sus padres, no puede beneficiarse de la inscripción de un vinculo generativo en el Registro Civil español, existe una extremada falta de certeza sobre quienes pueden ejercer la patria potestad, pues los padres comitentes no son más que guardadores de hecho, a lo sumo acogedores, del hijo del que deseaban devenir padres, y ... en caso de fallecimientos de estos, el niño no puede heredar.

El Tribunal Supremo español ha exhibido en su Sentencia de 6 de febrero de 2014 una argumentación tributaria del arsenal argumental de motivos éticos expuestos en el año 1986 en el Informe

4 A tenor del art. 116 del Código Civil español, "Se presumen hijos del marido los nacidos después de la celebración del matrimonio y antes de los trescientos días siguientes a su disolución o a la separación legal o de hecho de los cónyuges." 
Palacios que se recabó por el Congreso de los Diputados cara a adoptar criterios que debieran llevarse a la que sería nuestra primera Ley de Técnicas de Reproducción Asistida, la ya derogada Ley 35/1988, de 22 de noviembre, sobre Técnicas de Reproducción Asistida. $^{5}$

5 Recomendaciones de la Comisión Palacios. Informe de la Comisión Especial de Estudio de la Fecundación in Vitro y la Inseminación Artificial Humana (aprobado en el Pleno del Congreso de los Diputados en su sesión del día 10 de abril de 1986).

"Hay en la gestación de sustitución — se afirmaba en el informe- cuestiones de gran trascendencia a considerar, que pueden ser fuente de conflictos de intereses y desencadenantes de graves problemas entre la pareja estéril solicitante, la mujer sustituta o portadora, y el hijo, que en algunos casos pueden repugnar a su aceptación ética y en otros derivarían en interrogantes de carácter legal sin duda de difícil interpretación:

- Si la mujer portadora está casada o forma pareja estable, debiendo contar con el consentimiento del varón.

10 Informe de la Comisión Especial de Estudio de la Fecundación in Vitro.

- Si la mujer gestante contrae una grave enfermedad por efectos del embarazo, de carácter crónico, que pueda afectarla toda su vida.

- Si la mujer gestante contrae una enfermedad que puede producir graves anomalías al feto, por ejemplo, de tipo vírico, y la pareja estéril solicitante pide la interrupción del embarazo.

- Si se invierte el caso anterior y es la mujer estéril quien realiza o pretende realizar el aborto.

- Si la pareja solicitante se divorcia, o muere uno de los miembros o los dos, durante el embarazo.

- Si el hijo nace con malformaciones o anomalías y no es aceptado por la pareja estéril.

- Si la mujer embarazada no renuncia a la maternidad y desea que el hijo sea plena y legalmente suyo.

- Si existieran conflictos derivados de una comercialización descubierta por la crisis originada.

- Si la mujer gestante cede al hijo y ello le produce daños psicológicos de importancia.

- Si hubiere otras personas (la donante de óvulos, por ejemplo) con intenciones pleitistas, etc."

-Si el hijo reivindica su origen genético y obstetricia." 
En efecto, en el Informe Palacios se concluía que la gestación por sustitución debía ser rechazada, en parte por las dificultades jurídico-empíricas de su regulación y de su ulterior operatividad en el marco de la sociedad española; pero también por razones éticas, que son, sencillamente, las que con una dicción adaptada a la literatura postconstitucional, hemos leído en los Fundamentos jurídicos de la Sentencia del Tribunal Supremo de 6 de febrero de 2014:

[...] al considerar que hay una unidad de valor en la maternidad que en ella no se respeta y que crea una distorsión deshumanizadora. También, porque puede constituirse en una nueva forma de manipulación del cuerpo femenino (a la que la situación desfavorable de la mujer en el mercado puede contribuir), un abuso y una comercialización, a todas luces condenables y punibles $[\ldots]^{6}$

\section{EL DISCURSO DE LA DIGNIDAD}

Mucho se ha escrito a lo largo de los siglos XIX y XX, ${ }^{7}$ sobre la dignidad del ser humano, proclamada como principio básico de numerosos ordenamientos, y del nuestro en el art. 10 de la CE, se ha escrito mucho y se han escrito muchas proclamaciones ideológicas -antagónicas- con pretensiones de ser verdades reveladas. Es lo cierto que al amparo de la dignidad han combatido tanto los partidarios de hacer de ella un arma contra la maternidad subroga-

6 Años después, y hasta muy poco antes de promulgarse la vigente Ley 14/2006, el principal responsable de este Informe, el Profesor Palacios Alonso, seguía postulando la necesidad de mantener la prohibición del art. 10 de la primitiva Ley 35/1988, con los mismos argumentos Palacios Alonso, M., "Ley Sobre Técnicas de Reproducción Asistida (35/88): de 1988 a 2005" en Estudios jurídico penales sobre genética y biomedicina, Libro homenaje al Prof. Dr. Ferrando Montovani, VV.AA. (Coord.: I. Benítez, L. Morillas, J. Peris), Dykinson, Madrid, 2005 p. 20.

7 A tenor de la Declaración Universal de los Derechos Humanos, de 10 de diciembre de 1948 "Todos los seres humanos nacen libres e iguales en dignidad y derechos y, dotados como están de razón y conciencia, deben comportarse fraternalmente los unos con los otros." 
da, como los defensores de la admisión de ésta como componente inseparable del derecho del ser humano a la procreación. ${ }^{8}$

A los juristas que estamos acostumbrados a pensar el Derecho - cada norma de Derecho- en términos de transversalidad de la dignidad y de los derechos fundamentales, nos parece claro que la proclamación de la dignidad humana en el art. 10 de la Constitución española es mucho más que un mero juicio moral. Pero algunos nos aventuramos a mantener que no hay nada indigno en facilitar a otros la paternidad, con sacrificio del propio cuerpo, siempre que ello no suponga la prestación de un servicio remunerado. La mujer que, sin percibir un precio, se niega como madre a sí misma a través de una subrogación contractual, le reconoce ese papel a otra mujer y juntas hacen posible el nacimiento de un vínculo filial.

8 Cfrr. Pérez Monge, M., "Cuestiones actuales de la maternidad subrogada en España: regulación versus realidad”, en Revista de Derecho Privado, julio-agosto 2010, pp 41-64; en cambio, A.J. Vela Sánchez considera que la dignidad debe llevarnos a la posición opuesta, es decir, a aceptar la existencia, asociada a esa misma dignidad humana de un derecho a la procreación. Cfr. Vela SÁnchez, A.J., "La gestación por sustitución o maternidad subrogada: el derecho a recurrir a las madres de alquiler. Cuestiones que suscita la Instrucción de la DGRN de 5 de octubre de 2010, sobre régimen registral de la filiación de los nacidos mediante gestación por sustitución", en Diario LA LEY, núm. 7608, 11 de abril de 2011, pp. 1 a 17; "Propuesta de regulación del convenio de gestación por sustitución o de maternidad subrogada en España. El recurso a las madres de alquiler: a propósito de la Instrucción de la DGRN de 5 de octubre de 2010", en Diario LA LEY, núm. 7621, 3 de mayo de 2011, pp. 1 y ss.; "Problemas prácticos del convenio de gestación por sustitución o de maternidad subrogada en nuestro ordenamiento jurídico", en Revista de Derecho de Familia, núm. 53, 2011, pp. 67 y siguientes; "De nuevo sobre la regulación del convenio de gestación por sustitución o de maternidad subrogada en España. A propósito de la Sentencia de la Audiencia Provincial de Valencia de 23 de noviembre de 2011 ", en Diario LA LEY, núm. 7815, 9 de marzo de 2012, pp. 8 y siguientes. La maternidad subrogada: estudio ante un reto normativo, Comares, Granada, 2012; y "La gestación por encargo desde el Análisis Económico del Derecho. Medidas anticrisis desde el Derecho de Familia”, en LA LET, núm. 8055, 2013, pp. 8 y ss. 
En mi opinión, la mujer que alumbra a un niño sobre el que no ejercerá la maternidad, haciendo posible el proyecto procreativo de otra mujer, no niega más de lo que da, ni se niega a sí misma como madre en una forma menos radical ni más censurable que la mujer que ingresa en una orden religiosa con voto de castidad, o se entrega al deleite sexual utilizando los medios anticonceptivos que la ciencia nos ha proporcionado y que hemos introducido en el mercado.

\section{iv. El comercio con el cuerpo de LA MUJer y LA VidA Del NIÑO POR NACER}

La posibilidad de convertir el cuerpo de la mujer gestante en una mercancía, sin duda origina un problema ético que puede engrosar el contenido del orden público internacional con la referencia a la moral como límite de la autonomía de la voluntad de las partes.

Al planteamiento del riesgo del mercantilismo que se ha manejado, por el Tribunal Supremo y por los distintos comités de ética que se han pronunciado sobre el asunto, se le pueden dirigir dos objeciones. Por un lado, el art. 10 de la LTRA establece la nulidad del contrato de maternidad por sustitución en todo caso, no sólo cuando la mujer gestante alquila su útero y su cuerpo entero, puesto al servicio de la maternidad de otros, sino incluso cuando lo hace a título gratuito. En estas últimas circunstancias no está en juego, desde luego, la conversión en mercancía lo que el Derecho español considera res extra commercium, ${ }^{9}$ ni tampoco puede decirse que se coloque a la mujer gestante, necesitada de recursos económicos, en la indigna situación de tener que renunciar a lo irrenunciable para poder subsistir. Por otro lado, sin cuestionar ni minusvalorar el papel director que tiene el Tribunal Supremo en la definición de los principios fundamentales de nuestro orden público interno

9 Cfr. Art. 1271 del Código Civil española: "Pueden ser objeto de contrato todas las cosas que no están fuera del comercio de los hombres, aun las futuras." 
e internacional, tendríamos que poner de manifiesto que, en los últimos años, el papel de la intención de los padres ha recibido un importante espaldarazo por parte del legislador y de la jurisprudencia de los Tribunales en el marco de la acciones de filiación.

Seguramente el argumento que con mayor fuerza puede impactar en la sensibilidad del ciudadano es el de la falta de igualdad económica de las partes. El panorama que nos ofrece el Alto Tribunal es el de un verdadero contrato forzado, en el que la mujer sumida en la pobreza presta su organismo a cambio de una limosna que necesita para sobrevivir. También se podría decir que el reconocimiento en nuestro sistema de cualquier forma de maternidad subrogada daría carta de naturaleza al control, sojuzgamiento y explotación de la mujer. ${ }^{10}$

Entiendo que tales argumentos han sido refutados con sólidas razones por los firmantes del Voto particular que se formuló a la Sentencia del Tribunal Supremo de 6 de febrero de 2014, haciendo notar que ese panorama que opone a la mujer depauperada y necesitada y a los comitentes ricos del hemisferio Norte, no se puede generalizar y no tiene por qué corresponder a la realidad, no justifica que se subestime la capacidad para consentir de la madre gestante, cuya declaración de voluntad es emitida ante una autoridad competente según los propios criterios de competencia judicial internacional del Estado del foro; velando esa autoridad porque se preste tal declaración con libertad y pleno conocimiento de las consecuencias.

La perspectiva de la desigualdad estructural del contrato de maternidad subrogada no nos puede impedir el abordaje de la cuestión desde el exigente mandato de un consentimiento informado que es nota

10 Cfr. Krimmel, H. (1995). "La posición en contra de la maternidad sustituta", en Decisiones de Vida y muerte, Sudamericana, (Eds. Luna, F. y Salles, A.); Buenos Aires, 1995; Storey, G., "Ethical Problems Surrounding Surrogate Motherhood", en Bioethics, vol. II, 5, 2000; Vasanti, J. y otros, "Surrogacy: the experiences of surrogate mothers", en Human Reproduction, vol. 18, 2003, nº 10, pp. 2196-2204. 
común e insoslayable en todos los ordenamientos extranjeros en los que se reconoce la validez del contrato de maternidad subrogada y del vinculo de filiación que el mismo es susceptible de originar.

En todo caso, los problemas, tanto económicos como técnicos que pueda plantear la prestación del consentimiento por parte de las madres portadoras o madres gestantes, puede subordinarse por la ley a una supervisión o control, que es susceptible de una extensísima gradación, sin excluir una supervisión judicial previa en un procedimiento de jurisdicción voluntaria. El Informe Preliminar de la Conferencia de Derecho Internacional Privado de La Haya nos habla de algunos sistemas que han optado por la aprobación previa de los contratos de maternidad subrogada

("pre-approval" of surrogacy arrangements); sistemas caracterizados por el dato de que los padres comitentes y la futura madre portante o madre gestante se someten a unos exámenes médicos y psico-sociales que tienen como finalidad determinar si mantienen el perfil humano apropiado para sumir los compromisos propios del caso -cara, principalmente, a evitar retractaciones o cambios de planteamiento vitales que originarían un daño o un riesgo de incertidumbre jurídica para los menores que nazcan de tales acuerdos. Esa aprobación previa, ya sea dispensada por órganos de la Administración o de la Jurisdicción, tiene por objeto, además, que las partes reúnen los requisitos establecidos en la ley (Informe, Apdo 17).

\section{Breve exposición del RÉgimen de A MATERNidAd SUBROGADA EN DOS ESTADOS MEXICANOS}

1. En tabasco, la gestación por sustitución está permitida para parejas heterosexuales legalmente casadas o que actúen como marido y mujer, es decir, que mantengan una convivencia. Sólo se admite la gestación subrogada con carácter altruista, es decir, sin compensación económica alguna.

La ley de este Estado contempla dos tipos de madres gestantes: por una parte, la madre gestante que podemos llamar propiamente 
sustituta, que es la que se presta a gestar en su cuerpo el embrión proporcionado por medio de las técnicas de reproducción asistida, por la pareja comitente. De este modo, no existe una vinculación genética entre esta madre y el niño por nacer.

En segundo lugar, una madre gestante--donante que no sólo presta su cuerpo para albergar el embrión, sino que, además, aporta sus propios óvulos a fin de hacer posible el inicio del proceso gestativo. Esta es una madre a la que podría aplicársele el criterio gestativo. ${ }^{11}$

Desde la última modificación del Código Civil, la maternidad subrogada en Tabasco ha quedado relegada exclusivamente a ciudadanos mexicanos, por lo que ha dejado de ser, como lo fue en otra época, un paraíso procreativo, destino de parejas, por ejemplo, europeas.

La nueva normativa sobre la maternidad subrogada en este Estado ha originado un agria polémica entre los partidarios y detractores del proyecto procreativo. En el Código Civil se reconoce la maternidad subrogada como una actividad procreativa válida, sustentada en el acuerdo de los interesados.

11 Los tres criterios fundamentadores de la paternidad Tales criterios han sido magistralmente concretados en la doctrina italiana por la profesora CAMPIGLIO:

1) Criterio genético: es padre el que aporta el material genético que va a formar el genotipo del niño. La LTRA toma este criterio como base para la atribución de paternidad al titular del material genético masculino en los casos de maternidad subrogada, siempre que no sea un donante anónimo, pero le hace cargar con el pesado gravamen de ejercitar la correspondiente acción de reclamación de tal paternidad (art. 10.3.

2) Criterio gestativo. La madre - nunca el padre- es la que gesta con su cuerpo y alumbra al niño, prescindiendo de que haya sido fertilizada con material genético d otros, donantes conocidos o anónimos, o de que aporte el suyo propio.

3) Criterio social. Es padre el que está dispuesto a cumplir las obligaciones de tal, dentro de la unidad familiar y cara a toda la colectividad social, con efectos extraños que alcanzarán las tabulae del Registro, el nombre y apellidos, los alimentos y la sucesión mortis causa. CAMPIGLIO, C., "Lo stato di figlio nato da contratto internazionale di maternità", en Rivista de Diritto Internazionale Privato e Processuale, XLV, núm.3, 2009, pp. 589-604. 
En el caso de los hijos nacidos como resultado de la participación de una madre gestante sustituta, sin aportación de material genético propio, se presume la maternidad de la madre contratante o intencional, ya que la aportación de su propio material genético implica su aceptación. En los casos en los que participe una madre aportante de material genético, es ella la madre en sentido legal y la transferencia de la maternidad debe operarse a través de la adopción plena.

En cambio, la madre en el doble sentido que hemos apuntado, que aporta sus óvulos, es reconocida como madre legal del niño. Tal como la ley establece, cuando la gestante tiene una vinculación genética con el nacido, entonces es reconocida como madre legal del bebé. En ese caso, la gestante deberá renunciar a esta maternidad en favor En el caso de no haber vinculación genética con el bebé, la madre intencional será reconocida como madre legal del nacido.

Lo que parece claro en la ley es que, con independencia de que los óvulos pertenezcan o no a la madre intencional, o a una donante, el destino final del niño es incorporarse a la familia de la madre intencional.

Para acceder a un tratamiento de gestación por subrogación, los padres intencionales deben ser hombre y mujer casados o en concubinato, y deben justificar su impedimento procreativo mediante un certificado médico que deben presentar ante la Secretaría de Salud de Tabasco. La madre intencional no puede tener más de 40 años. Por otro lado, los padres comitentes tienen la obligación de contratar un seguro médico de gastos mayores a la gestante que cubra tanto el embarazo como el parto y el puerperio (artículo 380 Bis 7 párrafo 3).

Tras el nacimiento del niño, los aspirantes a la paternidad deben someterse a un procedimiento de adopción plena, independientemente de que hayan aportado algún material genético en el proceso biológico procreativo; exigencia ésta que ha sido severamente criticada por la doctrina especializada, por la incoherencia que mantie- 
ne con la propia ley tabasqueña de filiación y adopción, pues no tiene sentido una doble atribución de la relación jurídico paternofilial, su ya existe un vinculo genético entre el niño y alguno de los padres.

Por lo que se refiere a la mujer Gestantes con aportación de su propios óvulos o material genético, debe tener entre 25 y 35 años, (artículo 380 Bis 95 sección 3).

Es a la Secretaría de Salud del estado de Tabasco a quien le incumbe la vigilancia de todos los procesos de gestación subrogada, siendo este organismo el que debe determinar el perfil clínico, psicológico y social de las madres gestantes, pudiendo recabar de las demás instituciones mediadoras, sanitarias o no, incluso de los órganos jurisdiccionales que hayan entrado en contacto con los padres comitentes o intencionales, los informes necesarios.

2. La Ley de maternidad subrogada de Sinaloa exige igualmente que los futuros padres sean ciudadanos mexicanos para tomar parte en un proceso de gestación subrogada; y además, exige que la madre intencional sufra un impedimento o incapacidad procreativa. Sin embargo, un aspecto diferencial, de la mayor trascendencia, con respecto al régimen del Derecho de Tabasco, es que admite tanto la gestación subrogada altruista como la pactada con compensación económica.

Se dispone en el Artículo 283 de la ley sobre técnicas de reproducción asistida del estado de Sinaloa, que

La maternidad subrogada se efectúa a través de la práctica médica mediante la cual, una mujer gesta el producto fecundado por un hombre y una mujer, cuando la mujer, padece imposibilidad física o contraindicación médica para llevar a cabo la gestación en su útero y es subrogada por una mujer gestante que lleva en su útero el embrión de los padres subrogados, cuya relación concluye con el nacimiento.

Por lo que se refiere a la mujer gestante, la ley exige que tenga entre 25 y 35 años, que sea madre de un hijo consanguíneo sano, que presente una buena salud física y mental y que tenga capacidad 
para prestar el consentimiento voluntario de poner su cuerpo a disposición del proceso gestacional a favor de los padres intencionales

Además debe acreditar mediante dictamen médico que no ha estado embarazada durante el año previo a la implantación del embrión y que no ha participado más de dos ocasiones consecutivas en este procedimiento.

3. Mientras algunos Estados europeos tratan de superar la prohibición de la maternidad subrogada que haría realidad los suelos de numerosas parejas impedidas de procrear, otros Estados hermanos, en latinoamérica, tratan de avanzar en sentido inverso, prohibiendo lo que en los años pasados ha sido una realidad y una conquista jurídica.

En efecto, recientemente, algunos especialistas en Derecho de la Universidad Nacional Autónoma de México (UNAM) se han dirigido al Congreso de la Unión para que no se dé luz verde a las modificaciones de la Ley General de Salud con la que se generalizarían las practicas procreativas en torno a la maternidad por sustitución, en todo el país, toda vez que - se dice- con ello se atenta contra la dignidad humana.

Por lo que se refiere al Estado de Sinaloa, existe una propuesta de ley con intención de prohibir en el Estado de Sinaloa la gestación subrogada; aunque todavía no ha sido aprobada y por tanto no es más que únicamente Derecho proyectado, refleja un estado de opinión del pueblo mexicano que sigue, en su aspiración por un Derecho justo, impulsos de diferente signo en torno a la dignidad humana, el comercio de seres humanos, y la desigualdad estructural entre padres frustrados y potenciales madres gestantes.

\section{vi. Epílogo}

En la actualidad, España y México aparecen igualmente extraviadas en la búsqueda de la mejor defensa de la dignidad del ser humano. 
Los Estados tienen que tomar una decisión que venga a dar satisfacción a las necesidades sentidas por la comunidad, sin que el hecho de que carezcamos en España, no en México- de tradición histórica acerca de la maternidad subrogada, tenga el significado de una puerta cerrada, llamémosle orden público, ley de policía, fraude de ley o de cualquiera otra manera.

El estudio del Derecho comparado -y en particular, a los juristas españoles, el estudio de las legislaciones de algunos de los Estados mexicanos- nos ofrece muestras de regulación en las que se respeta la dignidad de la mujer alumbradora, que tanto le preocupaba al Tribunal Supremo español en aquella Sentencia de 6 de febrero de 2014.

En cuanto a la significación jurídica del comercio de seres humanos, se trata de una metáfora que tampoco puede suponer un obstáculo insalvable a través de una regulación cautelosa, que fije la compensación económica en favor de la madre biológica, no en razón del resultado del proceso de la gestación, sino del sacrificio orgánico y fisiológico que la sumisión a ese proceso, gestación y parto incluidos, le va a suponer.

Cualquier consideración de los derechos y expectativas de las partes involucradas debe considerar el nivel y la dimensión éticos de cada una de las cuestiones involucradas en la maternidad por subrogación, pues no otra cosa exige la contemplación de la dignidad humana y el valor justicia que inspira nuestra Constitución, lo que significa, cuando menos, que aspiramos a un Derecho justo.

De los diversos temores que puede inspirar un cambio de rumbo, no es el más pequeño el de que algún resquicio legislativo deje el paso franco al turismo reproductor, ${ }^{12}$ aunque también es cierto que tal peligro se conjuraría exigiendo la residencia habitual en España a, al menos, uno de los padres comitentes, solución adoptada en el Reino Unido y en otros Estados de la Commonwealth, o bien

12 Cfr. Vela Sánchez, A.J., "La gestación por encargo desde el análisis económico del Derecho. Medidas anticrisis desde el Derecho de Familia", en Diario La Ley, $\mathrm{n}^{\circ}$ 8055, Sección Doctrina, 4 de abril de 2013, año XXXIV, pp. 1-14. 
subordinando la licitud del contrato a la gratuidad de la prestación de la madre portante/gestante.

En el debate que anima a los juristas mexicanos y españoles, no puede prescindirse, por supuesto, de las opiniones de los Comités y Comisiones de Ética y de los profesores de filosofía del Derecho, algunos más encendida y enconadamente contrarios, cada día que pasa, al fenómeno de la procreación por sustitución.

Nada más lejos de mi intención la de cuestionar la legitimidad y la legitimación de estos Comités y profesores que en nombre de la ética demandan un abordaje controlado de las técnicas de reproducción asistida, para que el viaje que nos queda por hacer a todos, como especie sapiens, sea también un "viaje" controlado. Sin embargo hemos de puntualizar que NO le corresponde a ningún comité, conferencia o colegio, la última palabra en materia de ética. Las claves para la construcción del ser humano del futuro, y su configuración en clave de homo eticcus, nos concierne a todos: al Hombre de la Calle, a los padres frustrados, a los padres hipotéticos, a los espectadores, a las parejas homosexuales y heterosexuales, a los científicos que puedan o hayan de tener intervención en los procesos de la creación de la vida, a los niños y no tan niños que hayan sido procreados según las practicas autorizadas en las disposiciones legales sobre reproducción asistida, -disposiciones españolas y extranjeras- a los juristas y a todos los ciudadanos que esperan del legislador les proporcione unas coordenadas de vida en un marco de Derecho justo. 